\title{
DIMENSIONES JURÍDICAS INTERNACIONALES DE LA SEGURIDAD Y LA ESTRATEGIA DESDE LAS ORGANIZACIONES INTERNACIONALES EN RELACIÓN CON COLOMBIA ${ }^{1}$
}

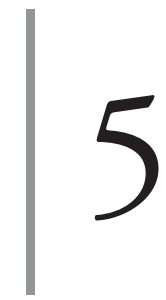

\author{
Jaime Alfonso Cubides Cárdenas \\ Ana Betty Cárdenas Herrera \\ Juan David González Agudelo
}

\section{Introducción}

El derecho internacional posmoderno parte de la disputa que se ha dado entre los idealistas kantianos y los realistas de la línea de Carl Schmitt. Disputa que en la actualidad gira en torno a si el derecho es el medio adecuado para hacer realidad sus objetivos, o si, por el contrario, el mejor medio es la política unilateral de una potencia o Estado (Habermas, 2003). Es decir, para comprender esto críticamente se deben considerar las dimensiones jurídicas internacionales de la seguridad y la estrategia desde las organizaciones internacionales, en especial en relación con Colombia.

Lo anterior, dado que los principales objetivos dentro de la esfera internacional de los Estados se han enmarcado en la defensa a la seguridad, la estabilidad, la consecución global de un núcleo intercultural, la democracia y los derechos humanos (Habermas, 2003). En otras palabras, todos los actores se rigen por unas reglas de juego que, a saber, son: ser por excelencia soberanos, control sobre sus límites, monopolio de la de violencia, capacidad de administrar justicia, reconocimiento internacional, capacidad para declarar la guerra, así como no hacer intervenciones en los asuntos internos de otros Estado (Habermas, 2003). Motivo por el cual, hoy se presentan sociedades caracterizadas por una alta actividad de ayuda

1 Capítulo de libro que expone resultados de investigación del proyecto titulado "Perspectivas de Seguridad y Defensa en Escenarios de Paz y Pos-acuerdo en Colombia", que forma parte de la línea de investigación "Desarrollo de procesos y sistemas de seguridad y defensa", del Grupo de investigación en ciencias militares, reconocido y categorizado Tipo B por Colciencias y registrado con el código COL0082556, vinculado y financiado por la Escuela Militar de Cadetes "Gral. José María Córdova”. Investigación con colaboración de la Escuela Superior de Guerra. 
humanitaria, capacidad de movilización con fundamento en la opinión pública y el poder de las emociones, con capacidad de establecer una comunicación en medio de la diversidad a través del reconocimiento de la diferencia, con fundamento en la cultura que se expresa en lenguas nacionales y literaturas (Habermas, 2003).

De cualquier modo, la secularización ve con desconfianza la política unida con el Estado, hecho por el cual la confianza en las organizaciones internacionales ha ocasionado que estas orienten unos lineamientos en cuanto seguridad y estrategia para los Estados, dado que la capacidad de dirección de estos se avizora con especulación frente a temas de seguridad, mercado, oferta, demanda y derechos humanos (Habermas, 2003). Por tanto, para evaluar críticamente el rol las organizaciones internacionales, así como sus dimensiones jurídicas internacionales en cuanto seguridad y estrategia, debemos advertir que Kant no alcanzó a percibir tres cuestiones importantes dentro de la realidad internacional, como lo son: la fuerza explosiva del nacionalismo, la superioridad de algunas civilizaciones y la imposibilidad de restringir el uso de la fuerza (Habermas, 2003).

Afirmación que se puede entender en relación con los postulados de Morgenthau, puesto que, en la política internacional, no son los méritos de las diferentes interpretaciones legales los que denotan poder, sino la distribución de este, por cuanto en una democracia es peligroso ser realista en materia interna y altamente idealista en política exterior. Por tanto, el equilibrio de poder que se halle en manos de la diplomacia debe buscar el método para preservar la paz y ofrecer una sociedad de Estados soberanos (Morgenthau, 1989). En definitiva, si el derecho internacional posmoderno quiere perdurar debe tomar como base el poder, puesto que este es una condición de la política y un criterio para su ejercicio en relación con la influencia, la autoridad, la persuasión, la disuasión, la inducción, la coacción, la compulsión y la fuerza, elementos diferenciados en la política que permiten imponer la voluntad en una relación social (Morgenthau, 1989).

Todo lo anteriormente planteado lleva a afirmar que hoy los Estados no están perdiendo sus competencias, por el contrario, están maniobrando sus políticas con base en tomar en consideración las dimensiones jurídicas desde las organizaciones internacionales (Colombia es un ejemplo de ello). Puesto que, en el campo internacional, los Estados comparten su soberanía con agencias globales no estatales, donde hay entidades supranacionales y alianzas regionales que velan por lineamientos en seguridad, economía y derechos humanos, es decir, los nuevos canales del "gobernar que van más allá de los gobiernos".

El presente escrito busca exponer, en primer lugar, el caso de América Latina como una integración indefinida, para lo cual se expone el contexto regional en 
relación con los conflictos. En segundo lugar, analiza la historia, rol y vigencia de la Organización del Tratado del Atlántico Norte (otAN), así como sus lineamientos en materia de seguridad. En tercer lugar, se ocupa del papel de la Organización Mundial de Comercio (OMc) en cuanto a las políticas económicas en relación con el crecimiento y proyección estratégica. Finalmente, se hace una revisión entorno al Sistema Interamericano de Derechos Humanos (SIDH), conforme a los aportes del Derecho Internacional Humanitario (DIH).

\section{América Latina, una integración indefinida}

La formación de los Estados en América Latina así como su integración han estado guiadas por unas situaciones paradójicas. Por una parte, se suele afirmar que el conjunto de Estados latinoamericanos registra la menor tasa de conflictos internacionales entre los siglos XIX y XX, y, por otra, si bien estos Estados registran una baja belicosidad internacional, no dejan de manifestar ni de experimentar una altísima tasa de violencia interna, caracterizada por guerras civiles, prácticas de bandidaje, persistencia de formas de resistencia armada como guerrillas y actividades delincuenciales (Patiño, 2010, pp. 55-56). Para ilustrar lo anteriormente enunciado, la figura 1 muestra la intensidad de las guerras, violencia, crisis, disputas y no conflictos en América durante los más recientes periodos históricos.

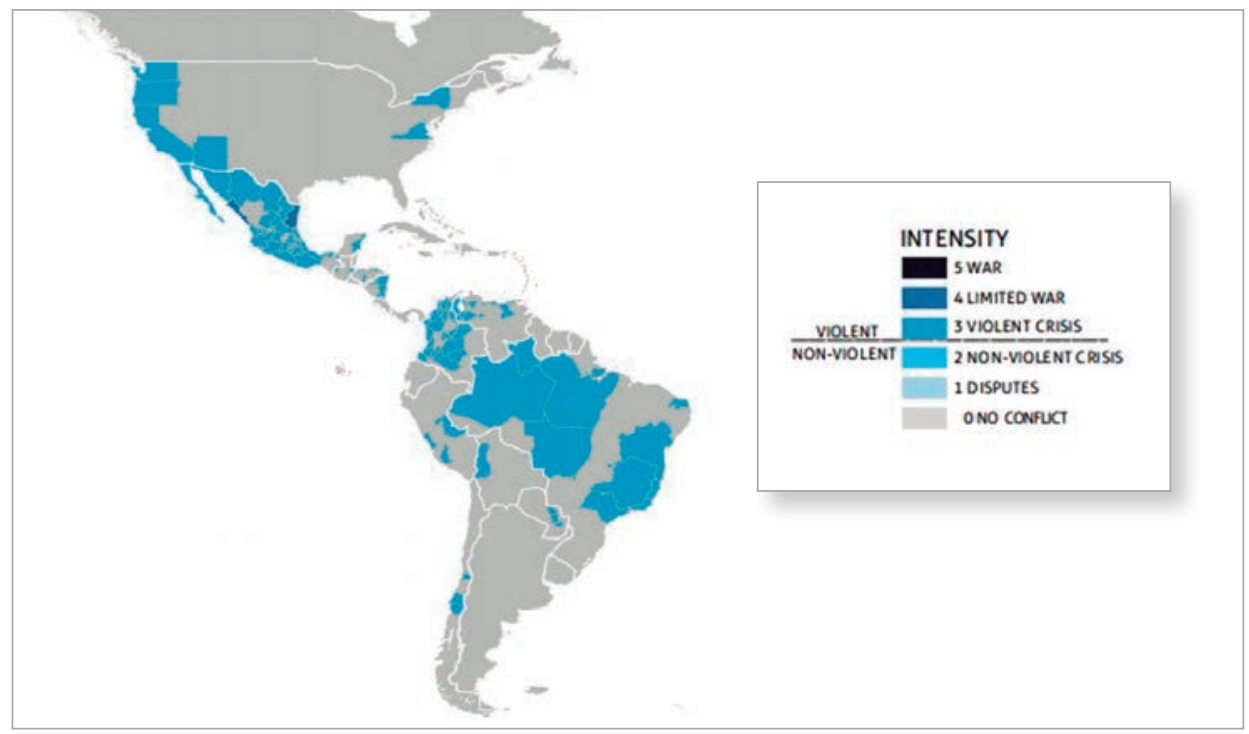

Figura 1. Intensidad de los conflictos en América.

Fuente: tomado de Heidelberger Institute for International Conflict Research (2017). 
Además, los países de la región se han caracterizado por una debilidad en política exterior y relaciones internacionales, pues desde el fin de la Primera Guerra Mundial, los países no se han nutrido de antiguas elaboraciones teóricas propias del derecho internacional y la diplomacia. Teorías que, pese a ser una construcción científica contemporánea, sustentan los análisis y apreciaciones que hoy facilitan la compresión de muchos de los fenómenos políticos, los cuales surgen dentro de los diferentes órdenes y sistemas hasta hoy conocidos. Tendencia que se puede confirmar y validar, puesto que entre los años 2016 y 2017 no se presentan amplias diferencias entre los conflictos históricos, tal como muestra la figura 2.

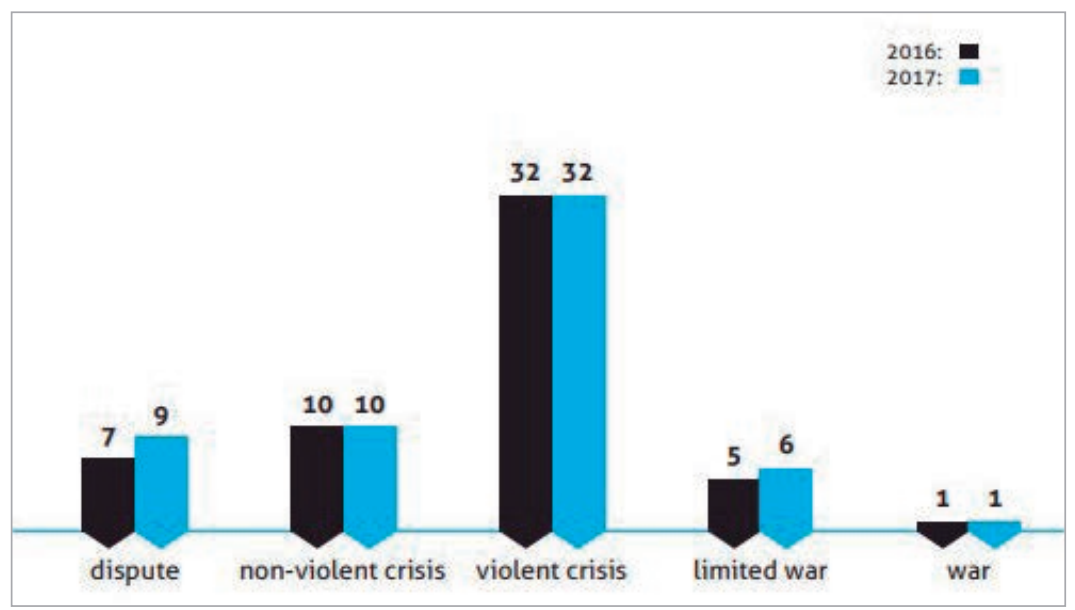

Figura 2. Comparación de conflictos en América 2016-2017.

Fuente: tomado de Heidelberger Institute for International Conflict Research (2017).

Aunque en política en América Latina las tendencias son contradictorias, dado que, por un lado, existe una importante frontera entre un grupo de potencias nuevas o emergentes (como Brasil, Colombia, Perú), y otro frente conformado por países con altos índices de inestabilidad política y económica (como Argentina y Venezuela) (Cuervo Ceballos, 2018), o aquellos afectados por la pobreza o la inseguridad (como Bolivia y América Central) (María, 1993). Es decir, hay una integración no uniforme indefinida, pues a partir del 2011 la Comunidad de Estados Latinoamericanos y Caribeños (Celac) nació como un órgano de concertación regional con vocación de convertirse en una organización internacional y competidora de la Organización de Estados Americanos (OEA), en especial en temas de seguridad (Sau, 2010). Además de la Celac, surgen nuevas iniciativas de integración como la Alianza del Pacífico, creada por Chile, Colombia, Perú y México, para 
avanzar en la integración comercial y coordinar en conjunto sus políticas frente a Asia y el Pacífico; algo muy positivo, porque reconfirma el compromiso con el comercio interregional e internacional (Foxley y Meller, 2014; González Martínez, Quintero Cordero y Ripoll De Castro, 2018).

Igualmente, se prevé que, en el próximo lustro, la región seguirá creciendo, principalmente Chile, Colombia, México y Perú (países con las tasas de crecimiento más elevadas), ya que hay una alta estabilidad macroeconómica que también se manifiesta en una inflación controlada. No obstante, ello está supeditado a una gran dependencia de las exportaciones de materias primas vinculadas a la demanda y la posibilidad de seguir avanzando en desarrollo tecnológico y científico. Ello, en parte, puede ser compensado por la creciente demanda que pueda surgir a mediano y largo plazo (Heredia, 2008). Además, el crecimiento económico y las nuevas políticas sociales facilitan la reducción de la pobreza y de la desigualdad. Sin embargo, de cara al 2025, algunos pronósticos prevén la superación de la pobreza en la región, pero es claro que los altos niveles de violencia y el populismo contribuyen a estas divisiones. Si continúa la tendencia actual, la violencia que ha alcanzado cifras récord en El Salvador, Honduras, Guatemala y Venezuela, y que aflige a gran parte de México y Brasil, continuará afectando la gobernabilidad y mermando el crecimiento económico (Foxley y Meller, 2014).

Finalmente, hay que señalar que la cooperación actualmente se está dando a tres velocidades: primera, relaciones especiales y horizontales con los socios estratégicos (Brasil y México); segunda, un diálogo privilegiado con las potencias medianas (Argentina, Chile, Colombia, Perú); y tercera, la tradicional cooperación norte-sur interregional con economías pequeñas o países de menor desarrollo (Bolivia y América Central) (Gratius, 2013). De lo anterior, se pueden destacar dos ejemplos: Alemania y Brasil, países que están aumentando sus vínculos económicos y políticos. A este respecto, y pese a las diferencias, es de esperar que la alianza bilateral se afiance, hecho que modificaría también el panorama de las relaciones europeo-latinoamericanas (Gratius, 2013). También China, competidor de la Unión Europea en el mercado latinoamericano, puede aumentar su injerencia con respecto a la negociación de un acuerdo de libre comercio con el Mercosur. Aunque la Unión Europea seguirá siendo un importante inversor y socio político, con una larga tradición, puesto que tiene prestigio en la región (Gratius, 2013). Lo anterior se explica porque la región se caracteriza por ser estable, ya que no hay grandes diputas por territorio, secesión, autonomía, poder nacional, poder internacional, recursos u otro tipo de disputas, tal como se evidencia en la figura 3. 


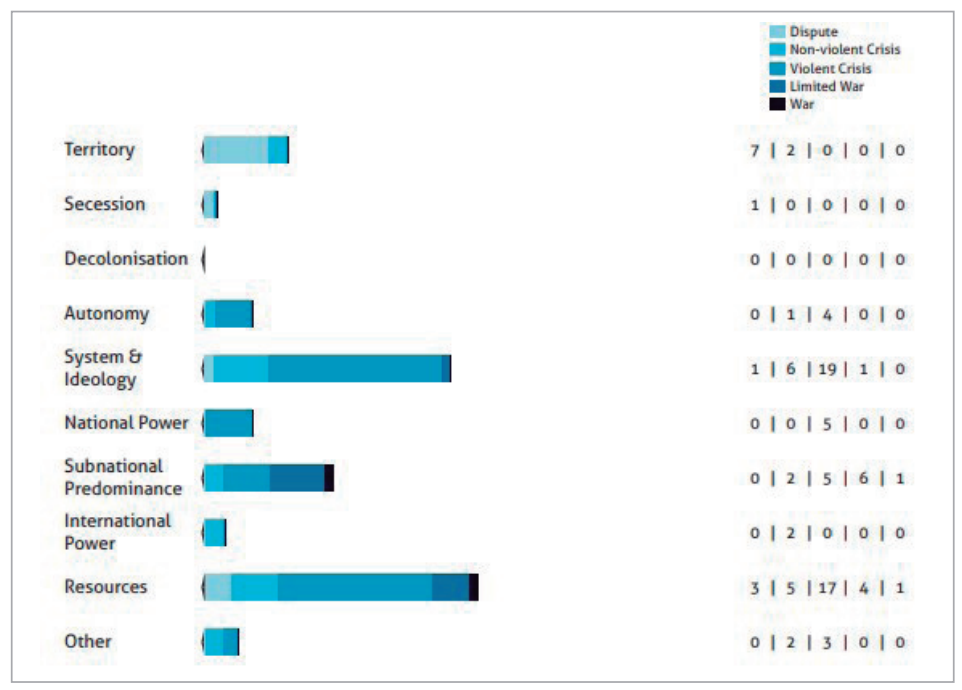

Figura 3. Tipos de conflictos entre los Estados en América 2017.

Fuente: tomado de Heidelberger Institute for International Conflict Research (2017).

Debido a las dinámicas de los conflictos actuales, los retos y desafíos de los Estados, especialmente los de América Latina, solo pueden ser explicados apropiadamente cuando comprendemos la frecuencia de los conflictos entre los Estados en relación con el tipo de conflictos, pues, en la coyuntura actual, hay unas dinámicas que se encuentran encaminadas, principalmente, al desarrollo de enfoques comunes sobre la seguridad regional, debido a que la tasa de conflictos entre Estados es cero, de acuerdo con el histórico estudiado, tal como se puede apreciar en la figura 4.

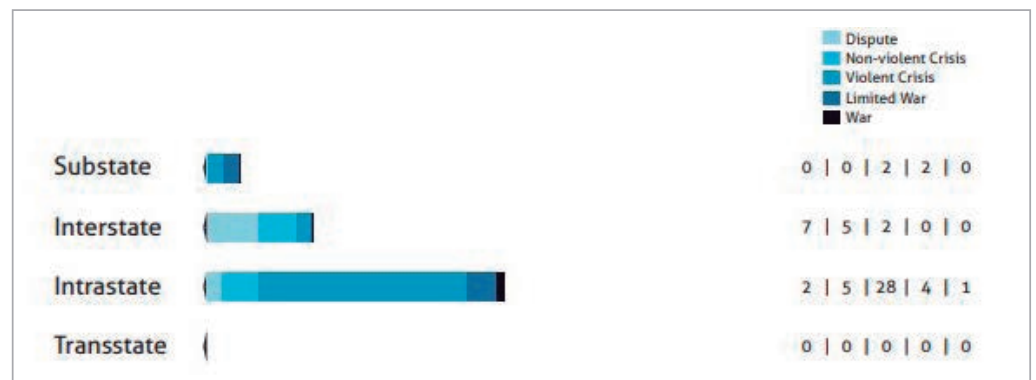

Figura 4. Frecuencia de conflictos entre los Estados en América 2017.

Fuente: t+omada de Heidelberger Institute for International Conflict Research (2017).

Finalmente, aunque el presente escrito, no pretende hacer un recorrido por las distintas organizaciones que se han creado en el continente americano (como Alalc, sela, Aladi, sicA, Caricom, CAN, Mercosur, ALBA, Unasur, tLCAN, DR-CAFTA, 
UE-LAC y la Comunidad Iberoamericana de Naciones), sí debe observarse que las nuevas amenazas que afectan la estabilidad y la paz en el continente hacen necesaria la cooperación hemisférica para combatir las diferentes actividades criminales que ponen en riesgo la estabilidad estatal (Americanos, 2003). Es decir, las nuevas amenazas, preocupaciones y desafíos para los Estados actuales, no son solo de carácter nacional, dado que el terrorismo, la delincuencia organizada, el problema de las drogas, la corrupción, el lavado de activos, el tráfico ilícito de armas, la pobreza extrema, la exclusión social, los desastres naturales, el deterioro del medio ambiente, la trata de personas o los ataques a la seguridad cibernética son retos para una integración indefinida (Americanos, 2003).

En definitiva, debido a la deslegitimación de las diferentes instituciones políticas tradicionales y en obediencia a los nuevos patrones de cambio a nivel mundial, América Latina, actualmente, tiene una crisis de soberanía nacional y gobernabilidad. Esto requiere que en las sociedades posindustrializadas, al igual que en las economías emergentes, se implementen modelos de 'flexiseguridad', lo que implica incorporar los lineamientos de organizaciones internacionales.

\section{Trato del Atlántico Norte}

La Organización del Tratado del Atlántico Norte (отAN) o North Atlantic Treaty Organization (NATO) en inglés, es una de las organizaciones que nace en el marco de la posguerra, entre la Segunda Guerra Mundial y en el inicio de la Guerra Fría, y que aún sigue vigente. No obstante, para poder hablar de la Guerra Fría y de organizaciones como la OTAN es necesario hablar primero del acontecimiento histórico del que ambas se derivaron, para ello hay que remitirnos a uno de los eventos más importantes y catastróficos del siglo xx: la Segunda Guerra Mundial.

\subsection{La Segunda Guerra Mundial}

La Segunda Guerra Mundial forjó el conflicto bélico más importante de la historia contemporánea, un enfrentamiento que tocó de manera directa e indirecta a casi todos los rincones del mundo, dejó más de 30 millones de muertos (SENA, 2007), países devastados, el uso de dos bombas nucleares y el campo minado para una tercera disputa que duró hasta finales del siglo xx. Si bien el tratado de Versalles supone el episodio de cierre de una primera fase bélica, se constituye también en el emblema de inconformidad y discordia que llevaría a la Segunda Guerra Mundial. Lo anterior porque en la década de los treinta la Alemania nazi, al mando de Adolf 
Hitler, desató una expansión ideológica y militar en la que pretendía la conquista de un nuevo imperio sobre los territorios de la Unión Soviética y Europa. El Imperio japonés suponía también la conquista de nuevos espacios por la vía militar sobre el Pacífico y el este de Asia, y en Italia el fascismo impuesto por Benito Mussolini aplicaba un régimen de marcado nacionalismo, en oposición al liberalismo y el comunismo, a través de la vía militar y con la pretensión de una expansión sobre el mediterráneo (United States Holocaust Memorial Museum, 2018).

Es decir, la dinámica binaria antitética del comunismo-fascismo, así como la conquista de nuevos territorios, llevó a estas naciones a firmar, el 27 de septiembre de 1940, el pacto tripartito: Berlín-Roma-Tokio, más conocido como 'el Eje’. Donde se reconoció la hegemonía alemana sobre la mayor parte del continente europeo, la hegemonía italiana sobre el mediterráneo y la hegemonía japonesa sobre Asia del Este y el Pacífico (United States Holocaust Memorial Museum, 2018). Hecho por el cual los opositores se embarcaron en una guerra que detonó en Europa el 1 de septiembre de 1939, con la invasión de Alemania a Polonia. Cabe resaltar que Alemania ya había adicionado a sus territorios a Austria y Checoslovaquia, sin embargo, Polonia había acordado su protección ante cualquier ataque con Francia y Gran Bretańa; Italia, por su parte, había invadido el sur de Francia para 1940 (United States Holocaust Memorial Museum, 2018).

En el caso de Asia la guerra se había detonado con anterioridad, cuando los nipones invadieron el territorio de Manchuria, al Norte China, en 1931. No obstante, el punto más álgido se alcanza cuando deciden bombardear territorios europeos y estadounidenses en el Pacífico, en 1941, entre ellos la base naval de Pearl Harbor en Hawái (United States Holocaust Memorial Museum, 2018). Los hechos históricos ilustrados, desencadenaron una respuesta militar estadounidense que ha sido, hasta el momento, el único ataque nuclear de la historia, ordenado por el presidente Harry S. Truman, donde fueron detonadas dos armas atómicas en territorio japonés en el año 1945: en Hiroshima la 'Little boy', el 6 de agosto, y en Nagasaki la 'Fat man', el 9 de agosto, las cuales dejaron una suma de muertos que es estima en más de 500 mil entre ambas (United States Holocaust Memorial Museum, 2018).

Según la Atomic Heritage Foundation, entre las muertes inmediatas a la detonación y las ocurridas en los meses posteriores por exposición a la radiación nuclear, la mayoría de ellas fueron civiles, aunque también murieron soldados y prisioneros de guerra. La guerra culminaría con la rendición de Japón el 15 de agosto de 1945, Alemania también se había rendido en el mes de mayo de ese mismo año y por su parte Italia había firmado una amnistía en 1943 (United States Holocaust Memorial Museum, 2018). De ahí que los catastróficos saldos del fin de 
la guerra llevaran a las naciones participantes a conformar diferentes sociedades y pactos, unos en aras de evitar nuevos enfrentamientos y otros con el fin de reforzar los lazos en caso de nuevos conflictos. Es por ello que hacia finales de 1945 la Organización de la Naciones Unidas (ONU) nace oficialmente con la firma de la carta que lleva el mismo nombre, en ella las naciones firmantes acuerdan diversos aspectos, pero principalmente, como lo especifica el primer apartado del primer artículo de la misma,

mantener la paz y la seguridad internacionales, y con tal fin: tomar medidas colectivas eficaces para prevenir y eliminar amenazas a la paz, y para suprimir actos de agresión u otros quebrantamientos de la paz; y lograr por medios pacíficos, y de conformidad con los principios de la justicia y del derecho internacional, el ajuste o arreglo de controversias o situaciones internacionales susceptibles de conducir a quebrantamientos de la paz. (ONU, 1945, art 1)

La carta fue firmada por 50 países, entre ellos los principales implicados en la Segunda Guerra Mundial. Después de esto, el mundo quedaría dividido en dos grandes bloques políticos y económicos. Además, en este lapso de la posguerra, nacen nuevos tratados y alianzas para defender los pactos ya existentes y los intereses propios de cada bando: de un lado el bloque occidental, cuya máxima expresión es el capitalismo, y de otro lado el bloque comunista, que reafirma los vínculos ya existentes con otras naciones comunistas del este europeo, para la defensa ante cualquier amenaza. En este contexto de polarización político-económico nace la OTAN y el Pacto de Varsovia, organizaciones que, se podría afirmar, son las que dan inicio a la Guerra Fría.

\subsection{La Guerra Fría}

La Guerra Fría como enfrentamiento ideológico, político, militar, económico, científico y cultural duró hasta la caída del Muro de Berlín, a finales de la década de los ochenta, y se prolongó otro tanto hasta la disolución de la Unión de Repúblicas Socialistas Soviéticas (URSs), a principios de los noventa. Este periodo se caracterizó por la tensión basada en el advenimiento de una posible guerra nuclear, además se llevó a cabo en zonas de interés para ambos bloques, especialmente en Asia, el Caribe y Latinoamérica. Donde los comunistas promovían y financiaban gobiernos de su misma índole y el bloque capitalista se dedicaba a promover golpes de Estado y la desestabilización económica y política. Entiéndase esta contienda como un enfrentamiento no directo, pero que evidencia interés en los territorios (Ministerio de Asuntos Exteriores y Cooperación, Gobierno de España, 2018). 
En otras palabras, a pesar de que la URSs había salido de la Segunda Guerra Mundial como una de las superpotencias, junto con Estados Unidos, la estabilidad de la zona europea del Este era débil. Motivo por el cual la dirigencia rusa se ve compelida a crear su propia alianza, el "Tratado de Amistad, Colaboración y Asistencia Mutua" o Pacto de Varsovia, que se establece en el marco de los principios de la Carta de las Naciones Unidas y se firma el 14 de marzo de 1955 en la ciudad polaca que le otorga el nombre. Los firmantes fueron los ocho gobiernos comunistas de la zona en cabeza de la Unión Soviética, Albania, Bulgaria, Checoslovaquia, Hungría, Polonia y Rumania (Ministerio de Asuntos Exteriores y Cooperación, Gobierno de España, 2018). En respuesta fue formulada la otan como un tratado de defensa militar frente a los miedos que producía y generaba la posibilidad de una revolución socialista, ello debido a la expansión que estaba generando el Estado soviético después de la Segunda Guerra Mundial (Ministerio de Asuntos Exteriores y Cooperación, Gobierno de España, 2018).

\subsection{Origen y perfeccionamiento de la OTAN}

En esta línea de argumentación, los orígenes de la OTAN la dan dos tratados, el primero fue el firmado entre Francia y Gran Bretańa el 14 de marzo de 1957, que tiene como nombre Dunkerque, y el segundo acordado en Benelux, entre Gran Bretaña y Francia el 17 de marzo de 1948, los cuales representan un acuerdo de defensa y mutua asistencia. Adicionalmente, en 1949 se firma el tratado de Washington el 4 de abril, que da vida a la OTAN amparado en el artículo 51 (capítulo viI) de la Carta de Naciones Unidas el cual establece que:

Ninguna disposición de esta Carta menoscabará el derecho inmanente de legítima defensa, individual o colectiva, en caso de ataque armado contra un Miembro de las Naciones Unidas, hasta tanto que el Consejo de Seguridad haya tomado las medidas necesarias para mantener la paz y la seguridad internacionales. Las medidas tomadas por los Miembros en ejercicio del derecho de legítima defensa serán comunicadas inmediatamente al Consejo de Seguridad, y no afectarán en manera alguna la autoridad y responsabilidad del Consejo conforme a la presente Carta para ejercer en cualquier momento la acción que estime necesaria con el fin de mantener o restablecer la paz y la seguridad internacionales. (ONU, 1945, art. 51)

Acuerdo que fue reafirmado por diez naciones emplazadas en su mayoría a ambos lados del Atlántico. Del norte de América: Canadá y los Estados Unidos de América. De Europa: Bélgica, Dinamarca, Francia, Islandia, Italia, Luxemburgo, Noruega, Países Bajos, Portugal y Reino Unido. Además de pactarse la cooperación mutua para la defensa ante cualquier ataque, las naciones firmantes o sus colonias 
crearon un bloque que reconoció la supremacía de Estados Unidos y su liderato en los asuntos tanto económicos como bélicos (North Atlantic Treaty Organization, 2016). De cualquier modo, para la década del cincuenta se adhieren al tratado, Grecia y Turquía en 1952, la República Federal Alemana en el 1955, y posteriormente España en 1982. A la estructura se unirán posteriormente otros países, incluidos antiguos miembros del Pacto de Varsovia, en la actualidad el tratado lo conforman 29 naciones (North Atlantic Treaty Organization, 2016). Para los fines del presente escrito, la OTAN ha tenido que mutar con el tiempo, por ello las diferentes contingencias históricas que lo atraviesan hacen que la organización comprenda en la actualidad una estructura tanto civil como militar, así como una red de organizaciones y agencias.

La primera fase de la estrategia tenía que ver con el periodo de inicio de la Guerra Fría, donde su labor consistía en alcanzar la paridad de la respuesta bélica a través de una carrera armamentística nuclear conocida como "Respuesta Masiva", cuya industria sería otro factor de beneficio para Estados Unidos, dicha estrategia preveía confrontaciones directas de exterminio total (North Atlantic Treaty Organization, 2016). No obstante, esta maniobra se mantendría solo hasta 1967 , año en el que adopta la estrategia de "Respuesta Flexible", ante la idea de la confrontación radical en la que el planeta desaparecería, por lo cual se comenzó a pensar en respuestas más ajustadas al tipo de confrontación, que permitieran una mejor gestión de las etapas y escalamientos del conflicto, lo que dejaba la repuesta nuclear como la última opción en la confrontación (North Atlantic Treaty Organization, 2016).

Una segunda fase se da en 1991, tras la caída del Muro de Berlín y la disolución de la URRS, porque la organización pierde la que era su base, pero curiosamente en noviembre del mismo año, en Roma, es aprobado un nuevo concepto estratégico no solo para mantener a flote la organización, sino para reforzarla. Este hecho se da en cabeza del presidente estadounidense George W. Bush, quien establece un nuevo discurso político sobre la operación de la organización y plantea cambios como

una menor dependencia respecto a las armas nucleares, y grandes cambios en las fuerzas militares integradas de la Alianza: reducciones sustanciales en su tamaño y grado de alerta, mejoras de su movilidad, flexibilidad y adaptabilidad a las diferentes contingencias y un mayor uso de formaciones multinacionales (Ministerio de Asuntos Exteriores y Cooperación, Gobierno de España, 2018).

Sumado a lo anterior, se establecen otros enemigos en cabeza de las exrepúblicas soviéticas y la naciente amenaza en el Oriente Medio y los conflictos del Mediterráneo y los Balcanes (Gallardo, 2015). En consecuencia, se admite una modificación al 
artículo 5 del protocolo inicial, lo que permitirá realizar operaciones fuera de los territorios inicialmente delimitados en relación con el artículo 51 de la carta de la ONU.

Por lo tanto, luego de las transformaciones en la segunda gran fase de la organización, esta se vio envuelta en numerosas misiones y operaciones militares, como ejemplos se encuentran, en primer lugar, las misiones internacionales y operaciones militares de Guerra Fría (1949-1990), entre ellas: Operación Anchor Guard 1991, Operación Ace Guard 1991 y Operación Agile Genie 1992 (Torrijos y Abella, 2017). En segundo lugar, las misiones internacionales y operaciones posguerra fría terminadas (siglo XXI), entre estas: Fuerza Internacional de Asistencia para la Seguridad en Afganistán (ISAF), OTAN en Bosnia y Herzegovina, OTAN en la República Yugoslava de Macedonia, segunda guerra del Golfo, protección de eventos públicos, huracán Katrina, asistencia tras el terremoto de Pakistán, asistencia a la Unión Africana en Darfur, operaciones contra la piratería en el golfo de Adén y el Cuerno de África (Torrijos y Abella, 2017). Y, en tercer lugar, las misiones internacionales y operaciones vigentes en el siglo XXI, como: OTAN en Afganistán en 2015, отAN en Kosovo, monitoreo del mar Mediterráneo, apoyo a la Unión Africana, misiones de vigilancia aérea (Torrijos y Abella, 2017).

Cabe resaltar que, según información oficial, la organización no realizó ninguna misión en el periodo entre 1949 y el inicio de los noventas, así, una de las primeras misiones fue la intervención en la guerra de los Balcanes (North Atlantic Treaty Organization, 2016).

La OTAN debe lidiar con tensiones internas constantes entre los intereses políticos, económicos y sociales, ya que su capacidad va desde la vigilancia aérea, defensa contra misiles balísticos, preparación civil, lucha contra el terrorismo, ciberdefensa, guerra electrónica, atención médica, hasta armas de destrucción masiva. En otras palabras, los miembros que componen el tratado siempre están ante la inminente amenaza, hecho que obliga a dinamizar no solo su capacidad operacional, sino a incluir los nuevos desafíos en materia de seguridad en los que se pueden destacar tópicos como investigación, energía, ciencia y temas de género (Sepúlveda Soto y Rivas Pardo, 2017).

Es así como en pleno siglo Xxi, no se puede desconocer que, frente a una constante amenaza de ataques nucleares por las tensiones políticas, las operaciones en el mantenimiento de la paz incorporadas a la OTAN, por medio de misiones internacionales de naturaleza militar, seguirá teniendo más vigencia e injerencia que en su primer medio siglo de existencia (Hurtado Granada, 2017). A modo de ejemplo, la figura 5 muestra el resumen de los tipos de operaciones de mantenimiento de la paz vigentes actualmente. 


\begin{tabular}{|c|c|c|c|}
\hline Tipo & Acción & Actores & Ejemplos \\
\hline $\begin{array}{l}\text { Primera } \\
\text { Generación: } \\
\text { Mantenimiento } \\
\text { de la paz } \\
\text { tradicional }\end{array}$ & $\begin{array}{l}\text { Observación y } \\
\text { monitoreo } \\
\text { Separación de fuerzas } \\
\text { de combate } \\
\text { Uso limitado de la fuerza }\end{array}$ & $\begin{array}{l}\text { Personal militar } \\
\text { exclusivamente } \\
\text { bajo el mandato } \\
\text { de la ONU }\end{array}$ & $\begin{array}{l}\text { Primer Fondo de Emergencia de } \\
\text { ONU, Canal de Suez (UNEF I), } \\
1956-1967 \\
\text { Fuerza de mantenimiento de la paz } \\
\text { de ONU en Chipre (UNFICYP), } \\
1964 \text { a la fecha } \\
\text { Fuerza de ONU de observación } \\
\text { de la separación, Altos del Golán } \\
\text { (FNUOS/UNDOF), } 1974 \text { a la fecha }\end{array}$ \\
\hline $\begin{array}{l}\text { Segunda } \\
\text { Generación: } \\
\text { Mantenimiento } \\
\text { de la paz } \\
\text { complejo }\end{array}$ & $\begin{array}{l}\text { Asistencia humanitaria } \\
\text { Construcción } \\
\text { institucional } \\
\text { Promoción de los } \\
\text { partidos politicos } \\
\text { Protección de los } \\
\text { derechos humanos } \\
\text { Apoyo a elecciones } \\
\text { democráticas }\end{array}$ & $\begin{array}{l}\text { Personal milltar } \\
\text { y civil de ONU + } \\
\text { Organizaciones } \\
\text { no } \\
\text { gubernamentales } \\
\text { (ONG) }\end{array}$ & $\begin{array}{l}\text { Grupo de ONU de asistencia a } \\
\text { la transición, Namibia (UNTAG), } \\
1989-1990 \\
\text { Misión de observación de ONU en } \\
\text { El Salvador (ONUSAL), 1991-1995 } \\
\text { Autoridad de transición de ONU en } \\
\text { Camboya (UNTAC), 1992-1995 }\end{array}$ \\
\hline $\begin{array}{l}\text { Tercera } \\
\text { Generación: } \\
\text { Imposición } \\
\text { de la paz* }\end{array}$ & $\begin{array}{l}\text { Uso de fuerzas de } \\
\text { aire, mar y tierra para } \\
\text { restablecer la paz } \\
\text { Creación de refugios } \\
\text { seguros } \\
\text { Asistencia humanitaria }\end{array}$ & $\begin{array}{l}\text { Personal militar } \\
\text { y civil de ONU + } \\
\text { ONG }\end{array}$ & $\begin{array}{l}\text { Fuerza de Protección de ONU, } \\
\text { exYugoslavia (UNPROFOR), } \\
1992-1995 \\
\text { Misión de ONU en la Rep. } \\
\text { Democrática del Congo (MONUC), } \\
\text { 1999-2010 } \\
\text { Misión de ONU de apoyo a Timor } \\
\text { Oriental (UNMISET), 2002-2005 }\end{array}$ \\
\hline
\end{tabular}

Figura 5. Operaciones de mantenimiento de la paz.

Fuente: tomada de Peace Operations Training Institute.

\subsection{Lineamientos estratégicos en seguridad para Colombia}

El Ejército de Colombia concentra todo su poder, accionar y filosofía en una fuerza totalmente contrainsurgente, sin embargo, durante los últimos ańos el Ejército adquirió una capacidad de combate que pocos ejércitos en el mundo tienen, y que quizá muchos quisieran tener en este tipo de conflictos (Rojas, 2017).

Por lo anterior, con el propósito de seguir consolidando un proceso de modernización en el interior del Ministerio de Defensa, surgió la necesidad de replantear la estrategia con la cual se pudiera combatir estos grupos al margen de la ley, lo que llevó a la creación del Comité de Revisión Estratégica e Innovación, llamado CRE-I, en el cual se diseńó la estrategia del plan "Espada de Honor", para lograr la derrota final de los grupos narcoterroristas con un trabajo coordinado, conjunto e interagencial, que ha cumplido la mayoría de los objetivos trazados y que, por lo tanto, fue efectivo para el Estado colombiano (Rojas, 2017; Fernandez-Osorio, CufiñoGutierrez, Gomez-Diaz y Tovar-Cabrera, 2018).

Esta reingeniería institucional abrió paso a una mejora en los procesos realizados en el interior del Ejército, con miras al desarrollo de capacidades que respondieran a los nuevos retos y amenazas que se vislumbran en un mundo cada vez 
más globalizado. Un concepto operacional que evolucionó desde los postulados operacionales de la Batalla Aeroterrestre (1986), Operaciones de Dimensión Total (1993), Operaciones del Espectro Total (2008) y Operaciones Terrestres Unificadas (2012), dimensión estratégica necesaria que emplean en la actualidad los ejércitos alineados con la doctrina OTAN (Rojas, 2017; Fernandez-Osorio, 2017).

En este sentido, la doctrina que determina el empleo operacional se construyó dentro del marco de un orden jurídico integrado por normas, nacionales e internacionales (Ley de seguridad y defensa) que regulan el empleo de los medios y los métodos de combate, con el fin de cumplir los objetivos militares propuestos, con total apego a dichas normas (Rojas, 2017).

En este contexto, las misiones internacionales de naturaleza militar establecen algunas posibles ventajas, como lo explican Torrijos y Abella (2017), entre las cuales se pueden destacar, en primer lugar, la continuidad de la proyección del poder militar como instrumento de la política exterior colombiana. Es decir, una eventual participación en algunas misiones internacionales de la OTAN constituiría un elemento de apoyo a la estrategia diplomática, por cuanto se buscan alianzas y acercamientos internacionales para posicionar a Colombia como un líder en temas de la defensa y la seguridad, primero en el ámbito hemisférico y posteriormente en el global (Torrijos y Abella, 2017).

En segundo lugar, la posibilidad de cerrar brechas de capacidad operativa en el nivel de una alianza militar intergubernamental única en el mundo, esto en cuanto un acercamiento más estrecho de tipo militar y logístico a la OTAN, lo que puede tener dos efectos deseables y positivos en la fuerza pública:

primero, lleva a las autoridades estatales a repensar obligatoriamente la estructura de sus Fuerzas Armadas como producto de las exigencias de operar en el marco de la OTAN. Segundo, como consecuencia de lo primero y en la búsqueda de aproximarse a las necesidades y expectativas de la Organización, los gobiernos son más proclives a emprender programas importantes de modernización del brazo militar estatal, lo cual puede venir acompańado de medidas para aumentar la transparencia y el control civil del ejército, así como para actualizar equipos y lineamientos estratégicos, entre otras cosas (Torrijos y Abella, 2017, pp. 66).

En último lugar, la formación de capacidades desde el contacto con las experiencias militares más profesionales a nivel global, esto implica tomar el conocimiento como el resultado de una adaptación activa del organismo humano a su entorno, donde se reconoce la importancia de la formación de capacidades y saberes a partir del contacto con experiencias ajenas a su propia realidad y entorno (Torrijos y Abella, 2017). Por lo tanto, los acercamientos del Estado colombiano a la Alianza Atlántica han sido siempre llevados a cabo de manera estratégica y acertada, a pesar 
de que estas 'relaciones' datan de 2010. Al respecto, se logró identificar una suerte de línea de tiempo de tres etapas: una exploratoria, que inicia en 2006 y en la cual se contempló la posibilidad de que Colombia se convirtiera en socia de la OTAN bajo la categoría "miembro extra" o aliado "extra-OTAN", en el marco de un plan por conseguir un grupo de países latinoamericanos "amigos" de la Organización (Torrijos y Abella, 2017). La siguiente etapa, entre 2012 y 2013, fue de desarrollo sustancial y su producto fue la elaboración y firma provisional de un primer acuerdo con la otan, el cual consiste en un Convenio de Cooperación e Intercambio de Información. Cabe agregar que se trató del primer memorando de esta naturaleza que la Organización suscribió con un país latinoamericano (Torrijos y Abella, 2017). Finalmente, la tercera etapa, denominada fase residual, comprendió dos cuestiones: la finalización del trámite interno legal del Tratado Colombia-OTAN y la reflexión y las impresiones que deja este acercamiento aún no terminado (Torrijos y Abella, 2017).

\section{Organización Mundial del Comercio (OMC)}

La globalización financiera se puede entender como la transformación de los sistemas financieros y su relación con el cambio de régimen de crecimiento de los países de capitalismo avanzado. El mejor ejemplo de ello es el papel que cumple la Organización Mundial del Comercio (OMC) la cual se ocupa de las normas mundiales por las que se rige el comercio entre las naciones. Donde su principal función es velar por que el comercio se realice de la manera más fluida, previsible y libre posible.

\subsection{Tratar las diferencias de forma constructiva}

Debido a la expansión del comercio, las tecnologías de información y comunicación (TIC) y la globalización, el mundo hoy avanza tan rápido que se podrían dar o crear desacuerdos, aunque ello resulta muy incierto, porque, en la media en que se avanza tecnológicamente y comercialmente, los Estados actuales pueden acudir a la gran diversidad de organismos de carácter internacional para resolver por medio del consenso sus diferencias.

Sin embargo, para facilitar esto, deben estar regidos por un reglamento y normas que posibiliten el adecuado comercio; con ello se pretende alcanzar, básicamente, una solución de forma constructiva y armoniosa, que disminuya las tenciones y evidencie la cooperación y el interés de ayuda entre países, pues esta es 
la intensión de la OMC, como mecanismo de solución y mediador para la diversidad de conflictos que puedan presentarse.

Como ejemplo, cuando un collapsed state (Chevallier, 2011, p. 100), puede afectar el comercio, a causa de dos factores, principalmente: el primer factor como consecuencia de la falta de innovación; la cual implica, falta de desarrollo de nuevas soluciones a problemas viejos (Acemuglu y Robinson, 2012. En este sentido, la innovación es acumulativa e implica innovar a partir de innovaciones previas, como en el caso de la invención de la máquina de vapor que partió del presupuesto de tecnologías preexistentes (Acemuglu y Robinson, 2012). El segundo factor debido a las instituciones extractivas, instituciones que forman parte del ámbito económico o político. Pero hay que diferenciar dos cuestiones: la primera es que las instituciones políticas estipulan quién tiene el poder en la sociedad y determinan para qué fines pueden utilizarse (Acemuglu y Robinson, 2012); por ende, las instituciones políticas extractivas concentran el poder en manos de una élite reducida y fijan pocos límites al ejercicio del poder (Acemuglu y Robinson, 2012). El caso contrario se daría desde el punto de vista económico, ya que estas instituciones implican la extracción de recursos de un subconjunto de la sociedad para proporcionar beneficios a un subconjunto distinto, el de una élite (Acemuglu y Robinson, 2012). Generalmente ambas instituciones restringen el desarrollo económico al limitar el comercio (Acemuglu y Robinson, 2012).

\subsection{Un sistema basado en normas y no en el poder}

La imposibilidad de igualdad frente a todos es algo muy complejo, pero la organización sí da espacios y logra hacer oír la voz de pequeños países que son invisibilizados por los más grandes; además, les brinda garantías en los acuerdos y procedimientos que desarrollan, sin importar que sean ricos o pobres, lo que facilita realizar alianzas y compartir recursos al aprovechar las oportunidades con fundamento en la no discriminación y concertar acuerdos donde se incorporen ventajas para quienes tienen menos competitividad; con ello se logra consolidar un visión en los gobernantes y las sociedades en materia de las políticas comerciales actuales a nivel mundial. Esto es lo que conocemos como: rule-making, monitoring, dispute resolution y reinventing governement (Chevallier, 2011, p. 109). Estos cuatro conceptos están ampliamente relacionados, porque a partir de su adecuada integración dentro de un Estado se generan instituciones inclusivas, pero debe fijarse la distinción de inclusividad en las instituciones políticas y económicas.

Dado que las instituciones políticas inclusivas confieren poder a amplios sectores de la sociedad, eliminan instituciones económicas que expropian recursos 
a la mayoría o levantan barreras que limitan el normal funcionamiento de los mercados que solo benefician a un número reducido de personas (Acemuglu y Robinson, 2012). Las instituciones económicas inclusivas, por el contrario, se forjan sobre bases establecidas por las instituciones políticas inclusivas, de manera que tienden a reducir los beneficios de los que pueden disfrutar las élites enfrentándose a la competencia de mercado y limitadas por los contratos y los derechos de propiedad del resto de la sociedad (Acemuglu y Robinson, 2012). Ambos tipos de instituciones fomentan el desarrollo económico, de una nación.

Esto posibilita modelos de 'economía dual'; este paradigma fue propuesto en 1955 por Sir Arthur Lewis, quien sostenía que los países subdesarrollados están divididos en un sector moderno y uno tradicional. El sector moderno corresponde a la parte más desarrollada de la economía y se asocia con la vida urbana, la industria moderna y el uso de tecnologías avanzadas. El sector tradicional se asocia con la vida rural, la agricultura y las tecnologías atrasadas (Acemuglu y Robinson, 2012). Este modelo de economía dual lo representan países como Sudáfrica o Colombia, entre otros.

Finalmente, como consecuencia de estos procesos, aparece el círculo virtuoso, que hace referencia a un proceso de "retroalimentación positiva" que protege a las instituciones políticas y económicas inclusivas de verse menoscabadas (Acemuglu y Robinson, 2012). Surge de las instituciones políticas inclusivas, las cuales favorecen el terreno en el que germinan instituciones económicas también inclusivas (Acemuglu y Robinson, 2012). Es el caso de la Inglaterra posterior a la Revolución gloriosa, en la que instituciones políticas llamadas a proteger el Estado de derecho y los derechos de propiedad permitieron la inclusión de más personas en el modelo económico, todo ello fue posible gracias a los incentivos, lo que luego se tradujo en una ampliación en la representación política.

\section{3 ¿Mayor libertad de comercio?}

La libertad económica permite a las personas adquirir alimentos, servicios, textiles, transporte y alimentos, lo que se da a menores costos (objetivo sobre el cual está estructurada la OMC), busca además la eliminación de obstáculos para reducir valores en importaciones y ayudar así a la reducción del gasto de cada persona. Es decir, se pretende que los países aumenten sus exportaciones con menores costos en aranceles y que ingresen importaciones sin restricciones, lo que genera ganancia para los empresarios e incentiva a los inversionistas a mirar a estos países como objetivos de posible y futuro desarrollo, esto permite crear nuevos mercados al explotar sus potenciales recursos de manera eficiente y adecuada, en busca de que cada país 
gane en su campo de competitividad, de modo que se logre eliminar obstáculos para dar beneficio a la mayor cantidad de países en las diversas regiones del mundo.

No obstante, los rogue states y los failing states (Chevallier, 2011, p. 69), hacen uso de los incentivos económicos de la omc, los cuales consisten en que las instituciones económicas inclusivas dan forma a los incentivos económicos: incentivos para recibir una educación, ahorrar e invertir, innovar, adoptar nuevas tecnologías (Acemuglu y Robinson, 2012). Por tales motivos, las instituciones políticas dependen de los incentivos y estos determinan el éxito o el fracaso de un país (Acemuglu y Robinson, 2012). En otras palabras, muchos de los rogue states y los failing states, a lo largo de la historia, han hecho uso del concepto 'destrucción creativa', acuñado por Joseph Shumpeter, que implica sustituir lo viejo por lo nuevo. Regla que, por lo general, se da en los sectores nuevos que atraen recursos y los destinan a los viejos para mejorar en competitividad, pues las empresas nuevas quitan del negocio a las ya establecidas, lo que hace que las máquinas existentes queden obsoletas (Acemuglu y Robinson, 2012). Por dichos motivos, el crecimiento económico está necesariamente ligado a las tensiones y la desestabilización o mal conocida 'destrucción creativa' generalizada, máxime cuando se da mayor libertad de comercio (Acemuglu y Robinson, 2012).

Sin embargo, hay excepciones a la regla, puede existir crecimiento económico, como es el caso de la unión soviética cuya economía creció rápidamente, pero no pudo hacerse de forma sostenida por la falta de incentivos a la innovación y la resistencia de algunas élites (Acemuglu y Robinson, 2012). Todo ello se debió a la oposición a la destrucción creativa, la cual no es solo económica, sino política y que, en muchas ocasiones, surge de la libertad de comercio (Acemuglu y Robinson, 2012). Pues la destrucción creativa redistribuye la renta y la riqueza, así como el poder político (Acemuglu y Robinson, 2012).

\subsection{Más y mejores posibilidades de elección}

En actualidad, gracias a las importaciones de los diversos mercados del mundo, se nos permite encontrar todo tipo de prendas, lo que nos brinda más posibilidades de elección, al igual que incontables cantidades de productos de diversas regiones del mundo. De este modo, los productos locales pueden ser visibilizados de manera internacional, lo que permite el desarrollo y el aumento de las exportaciones, con ello se consiguen ingresos lucrativos tanto para países como para empresarios y se agrega valor a la mano de obra. Algunos neoestructuralistas como Zygmunt (2010) han manifestado que en la actualidad todos como seres humanos somos culpables, 
dado que tenemos más y mejores posibilidades, donde el yo, como sujeto, es quien más responsabilidad tiene ante los demás.

Lo anterior, puntualmente, porque los global leaders (Chevallier, 2011, p. 59), como los banqueros, se han desvinculado de su responsabilidad, pues en la actualidad más y mejores posibilidades de elección se encuentran en un círculo vicioso, lo que implica un proceso de "retroalimentación negativa" (Acemuglu y Robinson, 2012). Este nexo se da entre instituciones políticas extractivas e instituciones económicas extractivas, donde las primeras generan el caldo de cultivo para las segundas, y viceversa (Acemuglu y Robinson, 2012). Es por esta razón que las instituciones políticas extractivas no proporcionan control contra los abusos de poder (Acemuglu y Robinson, 2012). Es el caso de Uzbekistán, en donde el poder político ostentado por Islam Karimov y su descendencia sirve como sustento para las instituciones económicas extractivas, vinculadas principalmente a los recursos del algodón.

\subsection{Lineamientos estratégicos en economía para Colombia}

La formación del Estado en Colombia, en palabras de Fernando López-Alves (2003), puede interpretarse como un largo proceso contrarrevolucionario, pues constantemente se dieron cambios radicales y rápidos. Estos cambios se pueden ver reflejados en las constituciones, donde se puede destacar la Constitución del Estado de la Nueva Granada, la Constitución de la República de la Nueva Granada, la Constitución Liberal, la Constitución de la Confederación Granadina, la Constitución de los Estados Unidos de Colombia y la Constitución Política de la República de Colombia (vigente hasta 1991).

Hechos históricos que ayudaron acentuar la institucionalización, más no la economía, puesto que la historia reciente de Colombia (siglos XIX y xx) ha estado marcada por tres grandes periodos: 1) la violencia partidista (1920-1958), donde surgieron organizaciones de autodefensa lideradas por líderes populares, 2) la aparición de las guerrillas de carácter 'revolucionario' (1960-1980), quienes en el marco de la Guerra Fría establecieron como objetivo violencia para acceder al poder político, y 3) el impacto del narcotráfico (1990 en adelante) donde se dan asociaciones entre guerrillas o autodefensas y demás actores públicos o privados. Es decir, no ha existido uniformidad en cuanto lineamientos estratégicos para la economía en Colombia, si se toma en consideración el rol de organizaciones internacionales; quizás una explicación acertada es que el Estado colombiano ha vivido desde sus inicios una verdadera fragmentación, como señalan Carlos Alberto Patiño, Marco Palacios y Frank Safford. 
De ahí que el fraccionamiento en Colombia se puede ver reflejado en la primacía de las regiones sobre la autoridad central y el comercio como un factor poco unificador, pues cada región generaba un circuito comercial propio, lo que impidió un mercado nacional, y dada la multiplicidad de instituciones burocráticas el Estado se limitó a la posibilidad de expandir otros servicios (Patińo, 2010). Adicionalmente, los partidos políticos fueron los artífices de la organización política en Colombia, dado su papel predominante en la lucha armada y la acción colectiva, que fueron los motores para el crecimiento de la economía regional. La mejor muestra de ello es que en gran parte de la historia nacional los presidentes de Colombia provenían de las provincias, lo que contribuía a la cohesión de los partidos políticos y a la economía regional, más no a la nacional (López-Alves, 2003).

\section{Sistema Interamericano de Derechos Humanos (SIDH)}

La Convención Americana de Derechos Humanos no establece un catálogo de casos o circunstancias en los que una muerte producto del uso de la fuerza pueda considerarse justificada, por absolutamente necesaria según las circunstancias del caso concreto. A pesar de la existencia de instrumentos internacionales como los Principios Básicos sobre el empleo de la fuerza y de armas de fuego por parte de los funcionarios encargados de hacer cumplir la ley y el Código de conducta para estos. En este sentido, el SIDH ha establecido el cumplimiento de ciertas medidas con respecto al debido modo de actuar en caso de que resulte imperioso el uso de la fuerza, en especial tomando en consideración el Derecho Internacional Humanitario (DIH).

\subsection{Lineamientos en Derecho Internacional Humanitario para Colombia desde la Comisión Interamericana de Derechos Humanos}

Un hito importante es el caso 11.142 (Colombia), informe 26/97 aprobado el 30 de septiembre de 1997. Este es un caso conocido popularmente como 'el caso de la leche'. Este informe tiene varios párrafos relevantes en materia de DIH tanto para el sidH como para Colombia, uno contundente es el párrafo 131, el cual indicó:

Las disposiciones no suspendibles del artículo 3 común de los Convenios de Ginebra, rigen la conducta respecto a las hostilidades, vinculando tanto al Estado como a los grupos armados disidentes, en todos los conflictos armados internos. Colombia ratificó los Convenios de Ginebra el 8 de noviembre de 1961. En mayo de 1995, se adhirió a las disposiciones del Protocolo Adicional II de los Convenios de Ginebra. 
En este mismo sentido, también se precisa indicar otros literales, como el 140, 142, 167 a 178, los cuales demostraron que la protección del DiH está reconocida en el régimen jurídico colombiano. En especial, la Constitución Política de Colombia, en su artículo 214 numeral $2^{\circ}$, señala que: "en todo caso se respetarán las reglas del derecho internacional humanitario”, lineamento que es estratégico en seguridad para la conducción de las hostilidades, pues

las operaciones militares deben siempre conducirse dentro de las regulaciones y prohibiciones impuestas por la aplicación de las reglas del Derecho internacional humanitario. La primera de estas reglas es que un herido y/o combatiente capturado debe ser tratado humanamente. Esta regla reconoce que cuando algunos combatientes han cesado su participación en las hostilidades y no representan más una amenaza o un daño inmediato para el adversario, no califican más como legítimos blancos militares. (párr. 140)

Otro caso significativo es el informe de Colombia sobre la situación de derechos humanos del año de 1999. Estamos hablando de un informe de unas 450 página, en el que se abarcan múltiples temas, su capítulo IV, por ejemplo, trata sobre la violencia y la violación del Derecho Internacional de los Derechos Humanos y Derecho Internacional Humanitario. De este informe se puede resaltar que, de acuerdo con la Constitución colombiana, la Policía Nacional está formalmente subordinada al Ministerio de Defensa y, conjuntamente con las Fuerzas Militares, constituyen la Fuerza Pública del país. Esta estructura institucional, por sí misma, no viola ninguna norma del DIH (CIDH, 1999, párr. 64).

El informe también define el concepto de 'ataque indiscriminado', puesto que, frente a cualquier duda concerniente a la protección de personas en hostilidades, el núcleo esencial de los principios y preceptos básicos que regulan los medios y métodos de guerra deben velar por la protección de personas civiles en las hostilidades, la protección de bienes civiles (en especial propiedad cultural). Es decir, la protección a todas aquellas personas que no son, o ya no son, parte de las hostilidades, así como prohibiciones sobre medios de guerra proscritos en conflictos armados en la conducción de las hostilidades conforme a la costumbre y leyes de guerra (CIDH, 1999, párr. 74; Imbeault, 2018).

Finalmente, se puede citar el informe 112/10, Petición Interestatal PI-02 Franklin Guillermo Aisalla Molina, Ecuador versus Colombia. Este es un caso de Estado contra Estado, quizás, lo novedoso es que no es muy típico que los Estados denuncien a los Estados en los sistemas internacionales de protección de derechos humanos. Lo anterior, dado que los Estados normalmente resuelven sus conflictos de manera directa, más en la vía diplomática, por lo que rara vez acuden a estas 
instancias. Ejemplo de ello es que hasta la fecha solo dos denuncias han tenido lugar ante el SiDH. La primera denuncia la hizo Nicaragua contra Costa Rica, por un caso de una situación de migrantes, caso que no fue admitido. La segunda denuncia fue la que hizo Ecuador contra Colombia, por la famosa 'Operación Fénix' u 'Operación angostura', hechos que ocurrieron el 1 de marzo de 2008, episodio en el cual ocurrió un bombardeo y murió Raúl Reyes.

De la petición cabe señalar que el señor Franklin Guillermo Aisalla Molina era ecuatoriano, así que un punto que alega el Estado ecuatoriano es que esta persona fue ejecutada extrajudicialmente. Para este caso, el Estado ecuatoriano propone, que de acuerdo al derecho internacional que:

las únicas dos excepciones posibles a la regla que establece la territorialidad de la jurisdicción se refieren a operaciones militares o actos de agentes diplomáticos o consulares en territorio de otro Estado; que para que se considere que un Estado ha ejercido su jurisdicción de manera extraterritorial por operación militar en el exterior, se debe demostrar que existió una ocupación militar o que el Estado que despliega la operación ejerció control sobre el territorio del otro Estado. (párr. 81)

La denuncia resulta muy interesante en el análisis de competencia que hace la $\mathrm{CIDH}$, porque hay unos muy buenos párrafos dedicados al DiH y más porque en este caso hablan mucho del núcleo común entre Derechos Humanos y DiH, también se destaca que la Convención Americana sobre Derechos Humanos (CADH) y los Convenios de Ginebra comparten un núcleo común de derecho, pues ambos buscan proteger derechos como la vida, la integridad y la dignidad humana.

\subsection{Lineamientos en Derecho Internacional Humanitario para Colombia desde la Corte Interamericana de Derechos Humanos ${ }^{2}$}

El primer pronunciamiento de la Corte es el 'Caso Las Palmeras'. Este caso ocurrió en el departamento de Putumayo, en Colombia, donde unos días antes de los hechos se había presentado un enfrentamiento entre el ELN y la fuerza pública, y unos maestros de una escuela resultaron muertos. La CIDH sostuvo que

se debía declarar que el Estado colombiano, no solo había violado los derechos contenidos en el artículo 4 de la CADH relacionado con el derecho a la vida, sino que también había violado el artículo 3 común de los Convenios de Ginebra del 12 de agosto de 1949. (CIDH, 2001, párr. 3)

2 La jurisprudencia de la Corte Interamericana de Derechos Humanos ha sido reconocida por los tribunales internacionales como una de las más activistas en materia de protección (Cubides y Vivas, 2012). 
Como respuesta a lo anterior, el Estado colombiano argumentó la falta de competencia material de la Corte. En cierta medida, lo que alegaba el Estado colombiano era que diferenciaba entre interpretar y aplicar disposiciones de los convenios en relación con la CADH. En otras palabras, la Corte Interamericana no podía atribuirle responsabilidades al Estado colombiano con instrumentos de DIH. No obstante, lo anterior no significa que la CIDH renuncia a la tarea de armonizar los diferentes instrumentos internacionales, por el contrario, esto refleja que la Corte busca incorporar instrumentos del DIH para interpretar las disposiciones normativas de la $\mathrm{CADH}$, en especial en lo referente al contexto de los conflictos.

Un segundo caso importante es la masacre de Mapiripán versus Colombia, hechos ocurridos en el departamento de Meta, donde miembros de las Autodefensas Unidas de Colombia (AUC) perpetraron esta gran masacre. Aquí la Corte señaló que esta masacre fue cometida en total desprotección a los civiles, por lo cual hace algunas referencias al DIH. Tal vez lo más interesante de esta sentencia es que, para darle fundamento y sentido al DIH, se cita el artículo 29 de la CADH, para señalar que las obligaciones del DiH pueden ser tomadas en cuenta por la Corte, en atención a que los tratados de derechos humanos son instrumentos vivos, cuya interpretación tiene que acompañar la evolución de los tiempos y las condiciones de vida actuales. En otras palabras, tal interpretación evolutiva es consecuente con las reglas generales de interpretación consagradas en la CADH y está de acuerdo con las establecidas por la Convención de Viena sobre el Derecho de los Tratados. En este sentido, al interpretar la Convención debe siempre elegirse la alternativa más favorable para la tutela de los derechos protegidos, según el principio pro hombre o pro persona (CIDH, 2005, párr. 106).

Finalmente, encontramos la masacre Santo Domingo versus Colombia. Esta masacre ocurrió el 13 diciembre de 1998, cuando una operación de la Fuerza Aérea Colombiana incurrió en un bombardeo donde murieron 17 personas, cuatro de ellas niños, y 27 quedaron heridas. En este caso la Corte acude al DiH como interpretación de la $\mathrm{CADH}$, en particular para interpretar el artículo 4.1. Básicamente, analiza y define tres principios: distinción, proporcionalidad y precaución, con fundamento en el derecho humanitario consuetudinario. A continuación, se transcribe en extenso el contenido de los párrafos más contundentes del caso:

[Principio de distinción]. De acuerdo a lo establecido por el Derecho Internacional Humanitario, el principio de distinción se refiere a una norma consuetudinaria para conflictos armados internacionales y no internacionales en la cual se establece que "[l]as partes en conflicto deberán distinguir en todo momento entre personas civiles y combatientes", que "[l] os ataques sólo podrán dirigirse contra 
combatientes" y que "[1] os civiles no deben ser atacados". Además, son normas de Derecho Internacional Humanitario consuetudinario las que disponen que "[l]as partes en conflicto deberán hacer en todo momento la distinción entre bienes de carácter civil y objetivos militares", de tal forma que "los ataques sólo podrán dirigirse contra objetivos militares", mientras que "los bienes de carácter civil no deben ser atacados”. Del mismo modo, el párrafo 2 del artículo 13 del Protocolo Adicional II a los Convenios de Ginebra prohíbe que tanto las personas civiles como la población civil como tal sean objeto de ataques (CIDH, 2012, párr. 212).

[Principio de proporcionalidad]. De acuerdo a lo establecido por el Derecho Internacional Humanitario, el principio de proporcionalidad se refiere a una norma consuetudinaria para conflictos armados internacionales y no internacionales, en la cual se establece que "[q]ueda prohibido lanzar un ataque cuando sea de prever que cause incidentalmente muertos y heridos entre la población civil, daños a bienes de carácter civil o ambas cosas, que sean excesivos en relación con la ventaja militar concreta y directa prevista”. El referido principio establece entonces una limitante a la finalidad de la guerra que prescribe que el uso de la fuerza no debe ser desproporcionado, limitándolo a lo indispensable para conseguir la ventaja militar perseguida. (CIDH, 2012, párr. 214)

[Principio de precaución]. De acuerdo a lo establecido por el Derecho Internacional Humanitario, el principio de precaución se refiere a una norma consuetudinaria para conflictos armados internacionales y no internacionales en la cual se establece que " $[1]$ as operaciones se realizarán con un cuidado constante de preservar a la población civil, a las personas civiles y los bienes de carácter civil”, y que "[s] e tomarán todas las precauciones factibles para evitar o reducir en todo caso a un mínimo, el número de muertos y heridos entre la población civil, así como los daños a bienes de carácter civil, que pudieran causar incidentalmente". Del mismo modo, la norma 17 de Derecho Internacional Humanitario Consuetudinario dispone que "[l]as partes en conflicto deberán tomar todas las precauciones factibles en la elección de los medios y métodos de guerra para evitar, o reducir en todo caso a un mínimo, el número de muertos y de heridos entre la población civil, así como los dańos a los bienes de carácter civil, que pudieran causar incidentalmente", y la norma 18 señala que "las partes en conflicto deberán hacer todo lo que sea factible para evaluar si el ataque causará incidentalmente muertos o heridos entre la población civil, daños a bienes de carácter civil o ambas cosas, que sean excesivos en relación con la ventaja militar concreta y directa prevista. (CIDH, 2012, párr. 216)

No obstante, este análisis que hace la Corte no es integral por cuanto no integra todos los principios, para interpretar la $\mathrm{CADH}$ con relación a los derechos contenidos en el instrumento internacional se puede profundizar en los párrafos 215 hasta el 228. 


\section{6. ¿Cómo comprender las dimensiones jurídicas de las organizaciones internacionales?}

Unos conceptos teóricos que nos permiten comprender las dimensiones jurídicas de las organizaciones internacionales son, en primer lugar, el concepto soft power (Chevallier, 2011, p. 69), que se utiliza en múltiples países en las relaciones internacionales cuando existen coyunturas críticas, las cuales son puntos de inflexión o de ruptura con las viejas instituciones. En la actualidad, en el rol de las organizaciones internacionales tiene mucha vigencia, ya que estas coyunturas son claves para redefinir el curso hacia el desarrollo económico, político o social, o terminan ocasionando el estancamiento. Evidentemente, por el simple devenir circunstancial de la historia, el azar o la contingencia, estos momentos pueden llevar a múltiples vías económicas y políticas y no están sujetas a una fórmula específica (Acemuglu y Robinson, 2012).

En segundo lugar, el concepto del rizoma, utilizado por Deleuze y Guattari, aunque es empleado desde un punto ampliamente filosófico, tiene como propósito describir realidades, por tanto, cualquier punto del rizoma puede ser conectado con cualquier otro, tal como se planteó en la presente discusión. De ahí que en la explicación del mismo no se fije un punto o este tenga un orden, pues el rizoma remite, necesariamente, a diversos escenarios a partir de lo lingüístico. Por tanto, no importa la naturaleza, pues la diversidad de formas permite conexión con él; por ejemplo, encontramos relaciones con lo biológico, lo político e incluso lo económico (Deleuze y Guattari, 1977). Dicho en otras palabras, un rizoma no cesaría de conectar eslabones semióticos, organizaciones de poder, circunstancias relacionadas con las artes, las ciencias o las luchas sociales (Deleuze y Guattari, 1977).

Además, el rizoma puede efectuar descomposiciones estructurales o explicar las mismas, lo cual es prácticamente lo mismo que buscar raíces (Deleuze y Guattari, 1977). Sumado a esto, el rizoma se plantea retos, pues no usa métodos populares, suele analizar el lenguaje descentrándolo sobre otras dimensiones, pero ello no hace que cambie la de la misma naturaleza, por el contrario, aumenta la multiplicidad (Deleuze y Guattari, 1977). Finalmente, un rizoma puede ser roto, interrumpido en cualquier parte, pero siempre recomienza y no cesa de reconstituirse, como en el caso de las organizaciones internacionales. Esta es quizás una de las características más importantes del rizoma (Deleuze y Guattari, 1977).

En tercer lugar, el concepto de liquidez de Bauman, puesto que para entender esta cuestión es necesario hacer una distinción entre modernidad sólida, la cual está empeñada en afianzar y fortificar el principio de soberanía territorial, exclusiva e 
indivisible, y en confiar esos territorios soberanos dentro de unas fronteras impermeables; y modernidad líquida, caracterizada por unas líneas fronterizas borrosas y sumamente permeables, con un intenso flujo de tráfico humano a través de todas las fronteras (Zygmunt, 2004). Es decir, es necesario entender que actualmente, más que nunca, nos esforzamos desesperadamente por captar la dinámica de los asuntos planetarios usando lo viejo, hábito perseverante y malo, ya que no permite organizar el equilibrio de poder con la ayuda de herramientas conceptuales como las de centro y periferia, jerarquía, o superioridad e inferioridad, dado que estas actúan más como un lastre que como recursos valiosos para entender las problemáticas actuales (Zygmunt, 2004).

Quizás por lo anterior, la principal amenaza para el individuo sigue siendo la falta de libertad o seguridad, valores indispensables para una vida digna que son difíciles de reconciliar y para los cuales todavía no se ha dado con el equilibrio perfecto entre ambos. Pues la libertad, a fin de cuentas, tiende a formar pareja con la inseguridad, mientras que la seguridad tiende a aliarse con las limitaciones de la libertad (Zygmunt, 2004). Decididamente, lo que se requiere es que la modernidad líquida, con su culto a la velocidad y a la aceleración, a la novedad y al cambio por el cambio, sea repensada. Sin embargo, con una notoria particularidad, la pertinencia para una entidad puede ser compartida y practicada simultáneamente junto con la pertinencia para otras entidades en casi cualquier combinación, sin que ello provoque, necesariamente, una condena ni unas medidas represivas de ninguna clase, es decir, Estado y organizaciones internacionales (Zygmunt, 2004).

Finalmente, encontramos el concepto de red de Castells, trabajo que se ha centrado en los movimientos sociales urbanos que han surgido en la sociedad, pero pone un especial interés en aquellos que se encuentran en la red. Por tanto, Castells plantea como hipótesis la superioridad histórica de las organizaciones verticales jerárquicas sobre las redes, con ello determina que la cultura de libertad fue y ha sido decisiva para producir las tecnologías de red. En otras palabras, se podría afirmar que las organizaciones internacionales siguen siendo estructuras que, aunque funcionan en red, buscan otorgar y garantizar derechos. Como ejemplos podemos plantear los movimientos libertarios como los ecologistas, el de Mayo del 68 en París, el de las libertades de expresión en Berkeley en 1964, que hacen un fuerte énfasis en la orientación hacia una transformación de los valores de la sociedad. Particularmente, Castells (2006) parte de la base de tres valores básicos fundamentales: el valor de la libertad y de la autonomía personal frente a las instituciones de la sociedad y el poder de las grandes empresas; el valor de la diversidad cultural y la afirmación de los derechos de las minorías, expresados en términos de 
los derechos humanos; y el valor de la solidaridad ecológica, es decir, el valor de la especie humana como un bien común.

En conclusión, en esta obra, como en muchas otras, no se tiene una formula única ni exclusiva para comprender el desarrollo social, la dimensión del Estado posmoderno y el derecho internacional de las organizaciones internacionales, pues en la actualidad, más que nunca, las sociedades siguen la ruta del libre mercado, la militarización y el respeto a los derechos humanos. Todo ello con el propósito de avanzar, pues el fin es asegurar una mejor calidad y bienestar para sus miembros. En definitiva, hoy sigue existiendo una alta tensión entre lo individual y lo colectivo, entre lo privado y lo público, entre lo global y lo local, características propias de las sociedades en desarrollo.

\section{Conclusiones}

El reto de las organizaciones internaciones sigue siendo hacer la distinción clásica entre la doxa y la episteme, es decir, entre la mera opinión y el conocimiento con un nivel de elaboración mucho más riguroso. Esto se debe a que no se hace uso o se carece del dominio de un léxico específico, lo que no permite diferenciar adecuadamente la doxa, esto limita conceptos que podrían explicar determinados fenómenos económicos y políticos, en nuestro caso, con mayor precisión y claridad. Dado que la opinión encuentra límites en el lenguaje a la hora de dar explicaciones, mientras que el conocimiento epistemológico se vale del dominio de herramientas conceptuales, o innova mediante la introducción de nuevos conceptos.

De otra parte, las fragmentaciones actuales y la escasa articulación entre entidades regionales en América Latina, siguen siendo un reto (Páez Murillo, Peón Escalante y Ramírez Pedraza, 2018). Sin embargo, el constante esfuerzo por conformar un espacio independiente latinoamericano podría dar frutos si se fortalece el liderazgo de Brasil, se robustece la Celac y, de una manera u otra, se mantienen estrechos lazos con Washington y relaciones de menor perfil con AsiaPacífico. Aunque es positivo tener varios interlocutores, es ilusorio pensar que se pueden concretar múltiples iniciativas ante las nuevas realidades del Sur y del Norte, pues la bilateralización, la cooperación y la inserción en los espacios transregionales aparecen como las opciones que sustituirán la vieja fórmula del interregionalismo, donde las organizaciones internacionales en temas de seguridad, economía y derechos humanos cobran vigencia.

Adicionalmente, los conflictos armados contemporáneos redireccionan el poder hacia aquellos vencedores cuya supremacía siempre ha sido notoria. Porque, 
si bien en el pasado el caballo de batalla se habría construido sobre la oposición entre el fascismo y el comunismo, al término de la Guerra Fría el nuevo mapa le otorga el poder a múltiples actores, lo que se convierte en una nueva dicotomía que tendrá su propio campo de batalla entre el Estado y las organizaciones globales. En suma, la participación en misiones internacionales relacionadas con la Alianza Atlántica prevé los llamados 'presupuestos bianuales de financiación común’ de la OTAN, ya que no hay acción o impacto sin costo (Torrijos y Abella, 2017). Esto hace necesario considerar las polémicas ante posibles violaciones de normativas locales e internacionales, lo que podría ser consecuencia de la irrupción de los llamados medios de comunicación masivos y las organizaciones internacionales, dada la difusión de información en tiempo real (Torrijos y Abella, 2017).

Paralelamente, la OMC no realiza control total sobre las diversas políticas implementas entre los países, porque son negocios celebrados entre cada Estado o país miembro de la organización, no obstante, las normas que se imponen entre sí son ratificadas por sus órganos de control, solo hay intervención e influencia por parte de la omc cuando alguna de las normas no es coherente, ni propicia, ni es adecuada para uno de los Estados miembros de la organización.

Finalmente, la transformación del Estado en Colombia se ha dado, en gran parte, desde el orden jurídico, especialmente orientado por disposiciones de diverso origen. Con respecto a los derechos humanos, por ejemplo, se ha guiado principalmente por el Derecho Internacional Humanitario; pero también por los Convenios de Ginebra y los aportes del sidh, pues la adecuación de un cuerpo doctrinario jerarquizado, moderno, factible y realizable, busca orientar y garantizar la revisión y adaptación de manuales, reglamentos, que estén acordes a la situación nacional, el entorno regional y el ámbito internacional.

En definitiva, pese a las dimensiones jurídicas de las organizaciones internacionales, y como se planteó en el debate inicial del presente texto, el derecho internacional posmoderno del mundo Occidental, se sigue poniendo en su centro de gravedad del Estado Social de Derecho: i) el núcleo moral, con fundamento en la libertad individual, ii) el núcleo económico, con fundamento en la libertad de competencia, el mercado y la propiedad privada, y iii) el núcleo político; sustentado en el reconocimiento de derechos, separación de poderes y la legalidad. Aunque, se pude también reflexionar que hay un exceso de eficacia formal, pues existe una amplia pérdida de soberanía con intervención económica desde diversas organizaciones internacionales. 


\section{Referencias}

Acemoglu. D. y Robinson. J. (2012) Por qué fracasan los países. Los orígenes del poder, la prosperidady la pobreza. Bogotá: Planeta.

Organización de Estados Americanos (2003). Conferencia Especial sobre seguridad. Conferencia Especial sobre Seguridad. México: Newsletter.

Atomic Heritage Foundation. (2014). Atomic Heritage Foundation. Bombings of Hiroshima and Nagasaki-1945. Recuperado de http://www.atomicheritage.org/history/bombings-hiroshima-and-nagasaki-1945

Castells, M. (2006). La sociedad red: una visión global. Madrid: Alianza.

Chevallier, J. (2011). El Estado posmoderno. Bogotá: Editorial Universidad Externado de Colombia.

Corte Interamericana de Derechos Humanos. (2001). Caso Las Palmeras vs. Colombia. Fondo.

Corte Interamericana de Derechos Humanos. (2005). Caso de la Masacre de Mapiripán vs. Colombia. Fondo, Reparaciones y Costas.

Corte Interamericana de Derechos Humanos. (2013). Caso Masacre de Santo Domingo vs. Colombia. Excepciones preliminares, Fondo y Reparaciones.

Constitución politica colombiana. (1991). Bogotá: Legis.

Comisión Interamericana de Derechos Humanos. (1997). Informe 26/97 Caso 11.142 Arturo Ribón Ávila (Colombia). Recuperado de https://www.cidh.oas.org/annualrep/97span/Colombia11.142.htm

Comisión Interamericana de Derechos Humanos. (1999). Tercer informe sobre la situación de derechos humanos en Colombia. Recuperado de http://www.cidh.org/countryrep/Colom99sp/indice.htm

Comisión Interamericana de Derechos Humanos. (2010). Informe 112/10, Petición Interestatal PI-02 Franklin Guillermo Aisalla Molina, Ecuador vs. Colombia.

Convención Americana de Derechos Humanos. (1969). Convención Americana de Derechos Humanos relativa a la protección de los derechos humanos de toda persona humana, 22 de noviembre.

Cubides, J. y Vivas, T. (2012). Diálogo judicial transnacional en la implementación de las sentencia de la Corte Interamericana. 8(2). pp. 184-204. Universidad Libre. Cali, Colombia.

Cuervo Ceballos, G. (2018). El crimen organizado transnacional como una amenaza híbrida para la Triple Frontera (Argentina, Paraguay y Brasil). Revista Científica General José María Córdova, 16(23), 43-61. https://doi.org/10.21830/19006586.304

Deleuze, G. y Guattari, F. (1977). Rizoma. Spanish Theory.

Fernandez-Osorio, A. (2017). The Participation of Colombia in United Nations' Multidimensional Peace Operations. Journal of International Peacekeeping, 21(1-2), 83 - 124. https://doi. org/10.1163/18754112-02101003

Fernandez-Osorio, A., Cufiño-Gutierrez, F., Gomez-Diaz, C., \& Tovar-Cabrera, G. (2018). Dynamics of State modernization in Colombia: the virtuous cycle of military transformation. Democracy \& Security, https://doi.org/10.1080/17419166.2018.1517332

Foxley, A y Meller, P. (2014). Alianza del Pacifico: en el proceso de integración latinoamericana. Santiago de Chile: Uqbar Editores.

Gallardo, Y. (30 de octubre del 2015). RT Noticias. ¿La OTAN otra vez? Recuperado de https://actualidad.rt.com/opinion/yizbeleni-gallardo/190015-otan-estrategia-culpa-desestabilizacion-mundo 
Gratius, S. (2013). Europa y América Latina: la necesidad de un nuevo paradigma. Barcelona: FRIDE

González Martínez, M., Quintero Cordero, S., \& Ripoll De Castro, A. (2018). La seguridad en la Alianza del Pacífico. Revista Científica General José María Córdova, 16(23), 63-80. https://doi. org/10.21830/19006586.102

Habermas, J. (2003). El derecho internacional en la transición exterior hacia un escenario posnacional. Madrid: Katz.

Heidelberger Institute for International Conflict Research. (2017). Conflict Barometer 2017. Recuperado de https://hiik.de/2018/02/28/conflict-barometer-2017/?lang=en

Heredia, E. (2008). Relaciones internacionales latinoamericanas: historiografías y teorías. Argentina. Estudios Ibero-Americanos, PUCRS, XXXIV(1), 7-35.

Hurtado Granada, M. (2017). Los límites del DIH a las armas autónomas. Revista Cientifica General José María Córdova, 15(20), 85-100. https://doi.org/10.21830/19006586.176

Imbeault, M. (2018). El destino de los civiles en la nueva guerra justa. Una perspectiva canadiense. Revista Científica General José María Córdova, 16(22), 23-36. https://doi. org/10.21830/19006586.322

López-Alves, F. (2003). La formación del estado y democracia en América Latina. Bogotá: Norma.

María, J. (1993). La integración en América Latina: objetivos, obstáculos y oportunidades. Montevideo: Centro de Formación para la Integración Regional.

Ministerio de Asuntos Exteriores y Cooperación, Gobierno de España (2018). Gobierno de España. Representación de España en la OTAN Bruselas. Recuperado de http://www.exteriores.gob.es/ RepresentacionesPermanentes/OTAN/es/quees2/Paginas/QueeslaOTAN.aspx

Morgenthau, H. (1989). Escritos sobre politica internacional. Madrid: Tecnos.

Organización de las Naciones Unidas (1945). Carta de las Naciones Unidas. Recuperado de: http:// www.un.org/es/sections/un-charter/chapter-i/index.html

North Atlantic Treaty Organization (NATO). (2016, 21 de diciembre). North Atlantic Treaty Organization (NATO). Operations and Missions: Past and Present. Recuperado de http://www. nato.int/cps/en/natohq/topics_52060.htm?

Páez Murillo, C., Peón Escalante, I., \& Ramírez Pedraza, Y. (2018). Contexto de la seguridad ciudadana en América Latina y el Caribe. Revista Científica General José María Córdova, 16(24), 83-106. https://doi.org/10.21830/19006586.360

Patińo, C. (2010). Guerra y construcción del estado en Colombia 1810-2010. Bogotá: Universidad Nacional de Colombia.

Peace Operations Training Institute. (2013). Study Peace and Humanitarian Relief Any Place, Any Time. Recuperado de http://cdn.peaceopstraining.org/2013/course_catalogue_2013.pdf

Restrepo, L. (2011). Proceso histórico de los derechos humanos en Colombia. Medellín: Universidad Autónoma Latinoamericana.

Rojas, P. J. (2017, enero-junio). Doctrina Damasco: eje articulador de la segunda gran reforma del Ejército Nacional de Colombia. Revista Científica General José María Córdova, 15(19), 95-119. Dor: http://dx.doi.org/10.21830/19006586.78

Sau, J. (2010). Nuevos temas en la integración latinoamericana del siglo XXI. Santiago de Chile: Friedrich Ebert Stiftung. 
SENA. (2007, mayo). Biblioteca Virtual Luis Ángel Arango. Actualización para periodistas-Evolución de los fenómenos políticos del siglo xx. Recuperado de http://www.banrepcultural.org/blaavirtual/ciencias/sena/periodismo/evopol/evopol3d.htm

Sepúlveda Soto, D., \& Rivas Pardo, P. (2017, enero 30). La mujer como sujeto de protección y de pacificación en la seguridad global: estudio del aporte teórico y conceptual del Gender Mainstreaming a las relaciones internacionales. Revista Cientifica General José María Córdova, 15(19), 123-144. https://doi.org/10.21830/19006586.75

Torrijos, V. y Abella, J. D. (2017, julio-diciembre). Ventajas y desventajas políticas y militares para Colombia derivadas de su eventual participación en misiones internacionales relacionadas con la отAn. Revista Cientifica General José María Córdova, 15 (20), 47-82. DoI: http://dx.doi. org/10.21830/19006586.175

United States Holocaust Memorial Museum (2018). Recuperado de https://www.ushmm.org/wlc/es/ article.php?ModuleId=10007245

Zygmunt, B. (2004). Modernidad Líquida. Buenos Aires: Fondo de Cultura Económica.

Zygmunt, B. (2010). Mundo consumo. Buenos Aires: Paidós. 
